\title{
Standards of Polish Society of Gynecologists and Obstetricians in management of women with diabetes
}

\author{
Ewa Wender-Ożegowska ${ }^{1}$, Dorota Bomba-Opoń ${ }^{2}$, Jacek Brązert ${ }^{3}$, Zbigniew Celewicz ${ }^{4}$, \\ Krzysztof Czajkowski ${ }^{5}$, Paweł Gutaj ${ }^{1}$, Aneta Malinowska-Polubiec ${ }^{5}$, Agnieszka Zawiejska ${ }^{1}$, \\ Mirosław Wielgoś ${ }^{2}$ \\ ${ }^{1}$ Division of Reproduction, Poznan University of Medical Sciences, Poznan, Poland \\ ${ }^{2} 7^{\text {st }}$ Chair and Department of Obstetrics and Gynecology, Medical University of Warsaw, Poland \\ ${ }^{3}$ Department of Obstetrics and Women's Diseases, Poznan University of Medical Sciences, Poland \\ ${ }^{4}$ Department of Obstetrics and Gynecology, Pomeranian Medical University, Szczecin, Poland \\ ${ }^{5} 2^{\text {nd }}$ Department of Obstetrics and Gynecology, Medical University of Warsaw, Poland
}

\section{INTRODUCTION}

The proposed standards are directed towards the management of diabetic women during pregnancy or puerperium, as well as, women who intend on becoming pregnant or whose hyperglycemia was first detected during pregnancy.

The recommendations are a revised version of the standards originally published in Ginekologia Polska in 2011 and 2015 , respectively. The update focuses on the nomenclature of diabetes in pregnancy standards of diagnosis and therapeutic goals, which define the proper management of diabetes in pregnancy.

\section{Classification}

The Polish Diabetic Society (PTD) classifies diabetes in pregnancy as follows:

- Pregestational Diabetes (PGDM) - when a woman with diabetes becomes pregnant (regardless of the type of diabetes)

- Hyperglycemia - first diagnosed during pregnancy (this group includes patients with gestational diabetes, as well as, other types of diabetes, diagnosed during pregnancy)

\section{PREGESTATIONAL DIABETES MELLITUS}

Despite the significant progress in diabetology, the risk of obstetric, maternal and neonatal complications remain substantially higher in patients with PGDM as compared to non-diabetic patients. For this reason, pregnancy in a diabetic should be managed in a specialized facility (III ${ }^{\circ}$ centre) with personnel experienced in managing PGDM pregnancy. The team should consist of:
1. Obstetrician
2. Diabetologist
3. Neonatologist
4. Educational nurse, dietitian

\subsection{Management model of pregnant patients with PGDM \\ 1.1.1. Preparing for pregnancy}

All diabetic women, who are planning a pregnancy, as well as, those in the course of pregnancy and/or postpartum, should remain under the care of an experienced diabetology-obstetrics team. The goal is to optimize the treatment of diabetes (including diabetic and dietetic education), increasing prevention, improving prognosis and treating its chronic complications (Tab. 1).

Due to the clinically proven negative impact of hyperglycemia on the fetus during the first trimester, the main goal of diabetologists and obstetricians should be providing care preceding pregnancy, referred to as the period of planning the pregnancy; optimally 3-6 months before conception.

All diabetic patients of childbearing age should be educated about irreversible complications and the potential 
Table 1. Classification of pregestational diabetes (modified P. White classification)

\begin{tabular}{|l|l|}
\hline Class $A^{*}$ & Sufficient glycemic control with diet alone; any duration of diabetes \\
\hline Class $B^{* *}(B 1$ and $B 2)$ & Onset after 20 years of age or duration less than 10 years** \\
\hline Class $C$ & Onset between 10 and 19 years of age or duration of $10-19$ years \\
\hline Class D & Onset before 10 years of age or duration more than 20 years or retinopathy or hypertension \\
\hline Class R & Proliferative retinopathy or hemorrhage to the vitreous \\
\hline Class F & Nephropathy; Proteinuria before pregnancy $>0.5 \mathrm{~g} / 24 \mathrm{~h}$ \\
\hline Class RF & Both criteria of class $\mathrm{R}$ and $\mathrm{F}$ \\
\hline Class H & Coronary artery disease, cardiomyopathy \\
\hline Class T & Post kidney transplant \\
\hline
\end{tabular}

* patients with impaired fasting glucose (IFG) and impaired glucose tolerance (IGT)

** diabetes type 2 before pregnancy

health impact of unplanned pregnancy on progeny, including birth defects.

\section{Contraception in diabetes}

Choosing an optimal method of contraception is indispensable to planning a pregnancy. This applies to patients who are planning the pregnancy, as well as, those who are not.

Patients should be informed that oral contraceptive pills are not contraindicated in diabetes. They should be examined in accordance with standard contraindications for hormonal contraceptives. Furthermore, patients should be able to make informed decisions about preferred contraceptive method - following education in regards to the risk of unplanned pregnancy [1]. The recommended method of contraception for patients with diabetes lasting longer than 20 years, or with vascular complications (nephropathy/retinopathy/neuropathy) is an intrauterine device (IUD) or progestin-only pills [2].

\section{Target glycemic levels}

It is recommended that a patient uses contraceptives until achieving optimal metabolic balance in the course of diabetes. It is essential that throughout pregnancy, and during the pregnancy planning period, patients achieve fasting and preprandial glucose levels of $70-90 \mathrm{mg} / \mathrm{dl}$ (3.9-5.0 mmol/L); maximum glucose levels 1 hour after meal: $<140 \mathrm{mg} / \mathrm{dL}(<7.8 \mathrm{mmol} / \mathrm{L})$; nighttime glucose between 2 and 4 a.m. > 70-90 mg/dL (> 3.9-5.0 mmol/L).

To evaluate the retrograde effectiveness of therapy occurring in the last 3 months, glycosylated hemoglobin (HbA1c) test is used. The recommended HbA1c level during the period of planning pregnancy and during the first trimester is $<6.5 \%$. It should be $<6 \%$ for $2^{\text {nd }}$ and $3^{\text {rd }}$ trimester.

Maintaining $\mathrm{HbA} 1 \mathrm{c}<6.5 \%$ (48 $\mathrm{mmol} / \mathrm{mol})$ during pre-conception period is linked to the lowest risk of fetal birth defects $[3,4]$.
The presented therapeutic goals provide optimal metabolic balance. In circumstances were such goals cannot be safely reached (risk of hypoglycemia), it is recommended that the goals be set at a less restraining level based on clinical experience and personalized care.

During the pregnancy planning period, type 2 diabetes patients should be switched from oral therapy to insulin therapy. Metformin is acceptable only during the pre-conceptual period provided that therapeutic doses ensure optimal metabolic control.

The use of metformin in women with diabetes type 2 is also allowed during the preconception period only if it provides the optimal control of the metabolic balance.

It is recommended that doctors providing care to women with diabetes type 2 of childbearing age discuss patients' plans for procreation on a regular basis - informing about the importance of planning pregnancy for reasons of risk of adverse obstetric outcomes in their population: coexisting obesity, dyslipidemia, hypertension treated with drugs that are contraindicated in pregnancy, advanced age at conception, lack of habitual intensive glycemic self-control.

\section{Ocular examination}

Patients with diabetes who are planning pregnancy should be informed about recommendations towards having undergone a fundoscopic examination in the past 6 months and then annually if no retinopathy is detected during first examination.

Patients should also be informed that an abrupt correction of metabolic balance in diabetes might lead to worsening of retinal changes $[5,6]$.

\section{Evaluation of kidney function}

During the process of planning pregnancy and prior to cessation of contraception, patients with diabetes are recommended to perform kidney function tests in effort to evaluate presence of albuminuria. Patients presenting 
with abnormal results of kidney function tests (blood creatinine $\geq 120 \mu \mathrm{mol} / \mathrm{L}$ and/or urine albumin: creatinine ratio $>30 \mathrm{mg} / \mathrm{mmol}$ and/or estimated glomerular filtration rate eGFR $<45 \mathrm{~mL} / \mathrm{min} / 1.73 \mathrm{~m}^{2}$ ), should be consulted by a nephrologist.

Patients should be advised that advanced kidney disease significantly increases the risk of complications during pregnancy, including preeclampsia and premature birth. Moreover, the risk correlates with the stage of kidney disease; there are also studies describing the progression of kidney disease during pregnancy [7-9].

\section{Evaluation of cardiovascular system}

Patients with following risk factors should be consulted by a cardiologist during the pregnancy planning period $[10,11]$ :

1. Presence of symptoms suggestive of coronary artery disease, limited exercise tolerance and/or congestive heart failure

2. Abnormal ECG results mentioned in patient history

3. Atherosclerotic changes in the carotid or peripheral arteries evidenced in patient history

4. Diabetes lasting longer than 15 years

5. In addition to diabetes presence of two or more ischemic heart disease (IHD) risk factors:
a) Age above 35
b) Abnormal lipid profile
c) Hypertension
d) Smoking
e) Family history of early onset atherosclerosis
f) Albuminuria (microangiopathy)
g) Autonomic neuropathy (macroangiopathy)

Successfully treated coronary artery disease (pharmacologically, $\mathrm{PCl}$, and/or surgically) is not a contraindication for pregnancy [12].

\section{Evaluation of thyroid function}

Evaluation as per recommendations of the Polish Endocrinology Society and the Polish Diabetology Society $[13,14]$.

\section{Folic acid supplementation}

Patients planning pregnancy should begin folic acid supplementation at least 12 months prior to becoming pregnant, with continued supplementation throughout the entire pregnancy, and during the postpartum and lactation periods.

The recommended supplementation for high-risk groups (pregestational diabetes type 1 and 2) is a folic acid dose of $0.4 \mathrm{mg} / 24 \mathrm{~h}$, increased by another $0.4 \mathrm{mg}$ dose, preferably in the form of activated folic acid. It is recommended that the supplemented formulations be enriched with vitamin B12 [15].

\section{Vitamin D supplementation}

The recommended dosage of vitamin $D$ supplements for a pregnant patient is 1500-2000 IU per day, while the recommended dose for patients with $\mathrm{BMI}>30 \mathrm{~kg} / \mathrm{m}^{2}$ may reach $4000 \mathrm{IU} / 24 \mathrm{~h}$ [16].

\section{Selected medications and their safety in early pregnancy}

Angiotensin-converting enzyme inhibitors (ACEI), angiotensin II receptor blockers (ARB), and statins should be ceased prior to conception, or as soon pregnancy is confirmed [17-19].

Safety of human insulin in pregnancy is well established; the most commonly used being short acting recombined human insulin (short acting analogs like Lispro and Aspart), intermediate acting recombined human insulin (NPH insulin) and long acting insulin analog Detemir (all mentioned types of insulin are classified into class B by FDA). Short acting insulin analog Glulisine and long acting insulin analog Glargine are categorized as class C according to the FDA. Long acting insulin analog Degludec has not yet been classified by the FDA.

Remaining diabetes medication has been classified by FDA as class B (metformin) or class C (sulfonylureas, pioglitazone, dapagliflozine, GLP-1 analogs). In regards to DPP4 antagonists, there is not yet enough research in the international journals about their safety in pregnancy.

It is contraindicated for a diabetic patient to get pregnant, when following clinical situations apply:

1. Nephropathy with creatinine clearance below $40 \mathrm{~mL} / \mathrm{min}$

2. Proliferative retinopathy resistant to treatment.

3. Cardiac complications:

a) Advanced ischemic heart disease not viable for treatment, hypertrophic cardiomyopathy or severe ventricular dysfunction (LVEF $<30 \%$, NYHA III/IV).

b) Previous perinatal cardiomyopathy, with any sort of residual dysfunction of left ventricle.

4. Autonomic neuropathy of the heart or gastrointestinal tract.

It is important to emphasize that any decision dealing with pregnancy belongs to the patient. Nevertheless, such individuals need to be informed by specialists about the risks associated with pregnancy in regards to patient health and life.

\subsubsection{Medical care of a patient} with pregestational diabetes mellitus during her pregnancy

In situations where pregnancy is unplanned and not managed by any specialized medical centre, it is strongly recommended to refer such patients as soon as possible.

Treatment involves reaching therapeutic goals in glycemia levels. Depending on the progression of pregnancy, 
hyperglycemia has different effects on the fetus. In the first trimester it significantly increases the rate of birth defects and miscarriage $[20,21]$.

The negative effect of hyperglycemia is a sort of continuum, where an increasing degree of glycemia increases proportionally the risk of adverse outcomes. The best results are achieved when glucose levels are close to levels set as goals $[22,23]$.

However, the patient should avoid excessively low glucose levels for reasons such as maternal hypoglycemia, or small for gestational age fetus.

Patients should be informed that pregnancy can affect glycemia control; in particular, pose an increased risk of severe hypoglycemia and increases demand for insulin during second half of pregnancy [11, 24].

Medical care of patients with PGDM should always be individualized.

Given the risks associated with pregnancy complicated with diabetes, it is recommended that routine visits in a specialized medical facility be scheduled at least every 2 weeks.

\section{Insulin therapy}

Insulin therapy is the recommended pharmacotherapy for pregnant women, regardless of diabetes type. Studies have shown that short acting insulin analogs (Aspart and Lispro) are more effective than human insulin in controlling postprandial glucose levels. There was no significant difference in obstetric outcomes [25].

Patients on insulin should be informed about the necessity of carrying fast-acting glucose (dextrose capsules, drinks rich in glucose) in the event of hypoglycemia.

In case of severe hypoglycemia, it is recommended to administer glucagon, which every patient with type 1 diabetes should be equipped with. Training on the use of glucagon should be offered to both the patient and her family.

Randomized studies concerning obstetric outcomes in patients with diabetes type 1 indicated no difference between patients using multiple daily injections (MDI) and patients using continuous subcutaneous insulin infusion (CSII) [26]. The decision about starting insulin pump therapy in a patient using MDI should be analyzed on an individual level. In particular, insulin pump therapy might be recommended for patients with recurrent episodes of hypoglycemia, especially occurring during the night [27]. Such groups of patients can benefit from a continuous glucose monitoring system (CGMS) [28, 29].

\section{Diabetic diet}

A diabetic diet is the basis of treatment for diabetes.

Patient with pregestational diabetes should receive a personalized dietary consultation that takes into account: pre-pregnancy BMI, physical activity level, dynamics of fetal growth and the recommended increase of maternal weight during pregnancy. An excessive increase of maternal weight can increase the risk of fetal macrosomia, which increases the risk of fetal injury during labor, the risk of caesarian section and obesity in the future [11].

An optimal range of body weight increase should be defined from pre-pregnancy BMI during first pregnancy checkup visit (Tab. 2).

A meal plan should be established together with the patient. Food intake should occur regularly and consistently throughout the day, with main meals and snacks that contain a proper amount of calories, including proteins $(1.1 \mathrm{~g} / \mathrm{kg} / 24 \mathrm{~h}$ ), fats (with < $10 \%$ of saturated fats) and $175 \mathrm{~g}$ of ingestible carbohydrates per $24 \mathrm{~h}$.

A diabetic diet assumes a balanced composition (40$-50 \%$ carbohydrates, primarily with low glycemic index, rich in starch and with limited amounts composed of processed flour; $20-30 \%$ of proteins of animal and plant origin (equal proportions); $20-30 \%$ of fats with the dominance of unsaturated fats of plant origin rich in omega-3, with a daily caloric intake adjusted to pre-gestational BMI, physical activity and age. A pregnant patient with normal BMI should consume $30 \mathrm{kcal}$ per $\mathrm{kg}$ of body weigh/24 h; the daily caloric intake for a pregnant woman should range from 1800 to $2500 \mathrm{kcal}$.

The daily meal plan should consist of 3 main meals and 3 snacks (first and second breakfast, lunch, afternoon snack, dinner, snack before bed). Fruits and simple carbohydrates should be integrated with main meals. Such division and meal composition guarantees a stable transfer

Table 2. Gestational weight gain recommendations (by Institute of Medicine, USA) in regards to pre-pregnancy BMI and daily caloric intake [30]

\begin{tabular}{|c|c|c|}
\hline $\begin{array}{c}\text { Pre-gestational BMI or BMI during first } \\
\text { obstetric evaluation }\left[\mathbf{k g} / \mathbf{m}^{2} \text { ] }\right.\end{array}$ & $\begin{array}{c}\text { Recommended gestational weight gain } \\
\text { (in }[\mathbf{k g}] \text { ) }\end{array}$ & $\begin{array}{c}\text { Recommended caloric intake } \\
\text { per kg of body weight }\end{array}$ \\
\hline$<19.8$ & $12.5-18.0$ & $35-40$ \\
\hline $19.8-26.0$ & $11.5-15.9$ & $30-32$ \\
\hline $26.1-29.0$ & $7.0-11.4$ & $25-30$ \\
\hline $29.1-34.9$ & below 7.0 & $24-25$ \\
\hline$>35.0$ & below 7.0 & $15-17$ \\
\hline
\end{tabular}




\begin{tabular}{|c|c|c|}
\hline \multirow{2}{*}{ Glucose measurement } & \multicolumn{2}{|c|}{ Glucose level } \\
\hline & {$[\mathrm{mg} / \mathrm{dL}]$} & {$[\mathrm{mmol} / \mathrm{L}]$} \\
\hline Fasting & $70-90$ & $3.9-5.0$ \\
\hline $1 \mathrm{~h}$ after meal & $<140$ & $<7.8$ \\
\hline Between 2 and 4 am & $>70-90$ & $>3.9-5.0$ \\
\hline Average 24 h glycemia & $<110^{*}$ & 6.1 \\
\hline
\end{tabular}

*Kitzmiller 2008 [11]

of nutrition to the fetus and allows for a better metabolic control of diabetes. The meal before bed is especially important; it prevents nighttime hypoglycemia and fasting ketogenesis. The bedtime meal should contain approximately $25 \mathrm{~g}$ of carbohydrates with a low glycemic index or products containing resistant starch. Morning ketonemia in a metabolically unbalanced patient can lead to intellectual disability and psychomotor retardation in her offspring [31].

\section{Monitoring glycemia}

Daily glycemic control is recommended for every pregestational diabetes patient on intensive insulin therapy. The control relates to fasting glucose levels in the morning, glucose levels before and $1 \mathrm{~h}$ following meals, and levels before sleep. Periodically, it is also recommended to control nighttime glucose levels between 2 and 4 AM. Patients with type 2 diabetes, who are treated with diet alone or with one dose of intermediate or long acting insulin, should control their fasting glycaemia and $1 \mathrm{~h}$ after meals (Tab. 3).

\section{Evaluation of ketoacidosis}

Patients with type 1 diabetes should carry strips that can detect ketone bodies in the urine. Urine ketone bodies' measurement should be performed when glycemic levels are above $200 \mathrm{mg} / \mathrm{dL}$. If ketones are detected patient should seek doctor [11].

In case ketoacidosis is suspected, patient should be referred to a facility with both obstetric ward and intensive care unit.

\section{Ocular evaluation}

Patients with pregestational diabetes, who have not undergone a fundoscopic examination in the past 3 months, should be examined as soon as possible and subsequently in the $28^{\text {th }}$ week of pregnancy. Patients diagnosed with retinopathy during their first visit should undergo an additional retinal exam between the $16^{\text {th }}$ and $20^{\text {th }}$ week of pregnancy.

Patients with a diagnosed retinopathy should undergo an ophthalmologic control 6 months after labor.
In cases of progressive retinopathy during pregnancy i.e. neovascularization or a clinically significant macular edema, laser therapy should be considered.

The presence of retinopathy alone is not an indication to terminate pregnancy via C-section. An ophthalmologist experienced in managing patients with diabetic retinopathy should advise recommended method of birth based on ocular indications. Nevertheless, in cases of neovascularization with the consequent risk of retinal hemorrhage, patients should avoid strong pushes during the second stage of labor or preferably be offered a C-section [11].

\section{Assessing kidney function}

If kidney function has not been assessed in the past 3 months, it should be assessed during the initial visit at a reference center. If plasma creatinine concentration is elevated (plasma creatinine $\geq 120 \mu \mathrm{mol} / \mathrm{L}$ and/or urine albumin:creatinine ratio $>30 \mathrm{mg} / \mathrm{mmol}$ or $24 \mathrm{~h}$ urine protein $>0.5 \mathrm{~g}$ ) the patient should be consulted by a nephrologist.

Estimated glomerular filtration rate (eGFR) should not be used to assess kidney function during pregnancy.

Arterial hypertension, including pregnancy-induced hypertension, should be closely monitored and treated. Based on observational studies, gestational diabetes mellitus (GDM) blood pressure targets of 110-129/65-79 mmHg may halt the progression of nephrological changes and prevent the development of preeclampsia $[32,33]$.

The recommended pharmacotherapeutic agents for treating hypertension during pregnancy complicated with diabetes are methyldopa, long-acting calcium channel blockers, and selective beta-blockers. Patients should also be advised to monitor their salt intake and body mass [34].

\section{Preeclampsia prophylaxis}

Patients with pregestational diabetes (type 1 and type 2) should take acetylsalicylic acid in the dose of $1 \mathrm{mg} / \mathrm{kg}$ of body weight (75-150 mg/day) from $12^{\text {th }}$ to $34^{\text {th }}$ week of pregnancy [35-39]. In our opinion, such prophylaxis should be indicated particularly in patients with a long history of diabetes with vascular complications, as well as, in patients with preeclampsia in previous pregnancies.

\section{HYPERGLYCEMIA FIRST DETECTED DURING PREGNANCY \\ 2.1. Hyperglycemia first detected during pregnancy - definition, classification and diagnostic criteria.}

Hyperglycemia first detected during pregnancy is defined as a various degree of glucose intolerance with onset or first recognition during pregnancy. Women whose hyperglycemia developed as a result of insufficient compensa- 
Table 4. Diagnostic criteria of GDM [WHO 2013, IADPSG]

\begin{tabular}{|l|c|c|}
\hline Glucose measurement & \multicolumn{2}{|c|}{ Plasma glucose concentration } \\
\hline Fasting & {$[\mathrm{mg} / \mathrm{dL}]$} & {$[\mathrm{mmol} / \mathrm{L}]$} \\
\hline 60 minutes & $92-125$ & $5.1-6.9$ \\
\hline 120 minutes & $\geq 180$ & $\geq 10$ \\
\hline
\end{tabular}

Because of differences in treatment, GDM is divided into two types:

G1DM - normoglycemia is attained by diet

G2DM - normoglycemia is attained by pharmacotherapy

tion of natural processes during pregnancy constitute the majority of this group.

A certain percentage of these women may have suffered from diabetes (mainly type 2 ) before their pregnancy without being diagnosed. This distinction has an important prognostic value to both pregnant women and their fetuses. For this reason, we propose the following classification and diagnostic scheme $[10,40,41]$

\subsubsection{Diabetes in pregnancy (DIP)}

- when blood glucose values in a pregnant woman exceed the levels necessary

for the diagnosis of clinically overt diabetes, i.e.:

1. fasting plasma glucose $\geq 126 \mathrm{mg} / \mathrm{dL}$ ( $7.0 \mathrm{mmol} / \mathrm{L}$ ) OR

2. plasma glucose 2 hours after a $75 \mathrm{~g}$ oral glucose tolerance test (OGTT) $\geq 200 \mathrm{mg} / \mathrm{dL}(11.1 \mathrm{mmol} / \mathrm{l}) \mathrm{OR}$

3. random plasma glucose $\geq 200 \mathrm{mg} / \mathrm{dl}$ ( $11.1 \mathrm{mmol} / \mathrm{L}$ ) with clinical symptoms of hyperglycemia

\subsubsection{Gestational diabetes mellitus (GDM)}

- when blood glucose values in a pregnant woman meet at least one of the diagnostic criteria (Tab. 4)

\subsection{The effect of gestational hyperglycemia on fetal development, newborn health and beyond}

In a pregnancy complicated by hyperglycemia first detected in pregnancy, carbohydrate metabolism disturbances and accompanying disorders of lipid metabolism occur usually in the second half of pregnancy; therefore, the main disorder accompanying this complication is excessive fetal weight (LGA, or large for gestational age, is a fetus above the $90^{\text {th }}$ percentile of weight for its gestational age), or macrosomia defined as a fetus with a mass above $4200 \mathrm{~g}$. These disorders may lead to shoulder dystocia, perinatal trauma and may be associated with a growing percentage of assisted deliveries.

Newborns with excessive birth weight often suffer from metabolic disturbances. Most typically, they suffer from hypoglycemia in the early perinatal period and have a higher risk of developing a cardiovascular disease - as well as obesity or type 2 diabetes. Randomized studies performed in recent years have shown that, when left untreated, even moderate carbohydrate tolerance disorders are associated with significantly increased risk of neonatal complications, while the implementation of therapy limits the incidence.

\subsection{Diagnosis of diabetes during pregnancy - management}

\subsubsection{Diagnostic algorithm for hyperglycemia during pregnancy}

Fasting blood glucose (FBG) should be ordered by a gynecologist as a routine laboratory test for all women in early pregnancy upon initial contact. Due to the differences in carbohydrate metabolism that occur during pregnancy, it is advisable to instruct the pregnant women before conducting the test that the break between her last meal and the test should last 8-10 hours. The break should not exceed that period since prolonged fasting may elevate fasting blood glucose.

a) FBG below $92 \mathrm{mg} / \mathrm{dL}$ and no GDM risk factors - the patient should be qualified for GDM testing between the $24^{\text {th }}$ and $28^{\text {th }}$ week of pregnancy.

b) FBG below $92 \mathrm{mg} / \mathrm{dL}$ and at least $\geq 1 \mathrm{GDM}$ risk factor:

- BMI before pregnancy $\geq 30 \mathrm{~kg} / \mathrm{m}^{\wedge} 2$

- GDM present in previous pregnancy

- family history (in first degree blood relatives) of type 2 diabetes

- giving birth to a child with a birth weight equal to, or over, $4.5 \mathrm{~kg}$

a $75 \mathrm{~g}$ OGTT should be ordered right away and if the results are within the normal range a repeated $75 \mathrm{~g}$ OGTT should be ordered between the $24^{\text {th }}$ and $28^{\text {th }}$ week of pregnancy.

c) FBG $93-125 \mathrm{mg} / \mathrm{dL}$ - immediately perform a $75 \mathrm{~g}$ OGTT

d) FBG $126 \mathrm{mg} / \mathrm{dl}$ or above - repeat the test and if the result is still $\geq 126 \mathrm{mg} / \mathrm{dL}$ a diagnosis "diabetes detected in pregnancy" should be made and the patient should be directed to a reference centre specialized in treating pregnant diabetics, without the need to perform OGTT. However, if the result of the repeated FBG is equal to $125 \mathrm{mg} / \mathrm{dL}$ or less, a $75 \mathrm{~g}$ OGTT should be ordered immediately.

e) 120 minute glucose plasma concentration $\geq 200 \mathrm{mg} / \mathrm{dL}$ - a diagnosis "diabetes detected in pregnancy" should be made and patient should be referred immediately to a reference centre specialized in treating pregnant diabetics.

f) random plasma glucose $\geq 200 \mathrm{mg} / \mathrm{dL}$ - a diagnosis "diabetes detected in pregnancy" should be made and patient should be referred immediately to a reference centre specialized in treating pregnant diabetics, without the need to perform an OGTT. 
g) in patients managed with diet and diagnosed with impaired glucose tolerance (IGT), or impaired fasting glucose (IFG) before pregnancy, a diagnosis of class A pregestational diabetes mellitus (PGDM) should be made upon confirmation of pregnancy and the patient should be directed to a reference centre specialized in treating pregnant diabetics, without the need to perform an OGTT.

h) if patient is treated with metformin prior to pregnancy due to insulin resistance, it is recommended to continue therapy and begin glucose monitoring (fasting and one hour following main meals) until the end of the first trimester. A $75 \mathrm{~g}$ OGTT should be performed seven days after discontinuing metformin.

\subsubsection{Conditions of performing a $75 \mathrm{~g}$ oral glucose tolerance test}

For the diagnosis of hyperglycemia during pregnancy, a single stage procedure is recommended in the form of a $75 \mathrm{~g}$ oral glucose tolerance test, performed on an empty stomach. Testing venous plasma is the recommended method.

a) the test should be performed 8-10 hours after the last meal;

b) for at least 3 days prior to the test, the pregnant woman should consume a diet with standard amounts of carbohydrates (not less than $150 \mathrm{~g}$ of carbohydrates provided normal activity level);

c) the solution consisting of $75 \mathrm{~g}$ of glucose dissolved in $250-300 \mathrm{~mL}$ of water must be consumed within 5 minutes;

d) during the duration of the test, the patient must sit and cannot eat or smoke cigarettes;

e) blood is drawn during the fasting state, at one hour and two hours after drinking the glucose solution;

f) if glucocorticosteroids have been given to the patient in order to stimulate fetal lung development, the test must be delayed until at least 72 hours after the glucocorticosteroid cycle is complete; likewise, the test should not be performed when the patient is on intravenous beta-adrenergic agonist therapy.

\subsubsection{Other laboratory tests}

a) it is advisable to measure $\mathrm{HbA} 1 \mathrm{c}$ at the time of diagnosis of GDM, especially in patients diagnosed during the first trimester, since the test may confirm or rule out the existence of undiagnosed type $2 \mathrm{DM}$ [42]. In the event of detecting $\mathrm{HbA} 1 \mathrm{c} \geq 6.5 \%$, at the moment of diagnosing GDM, the patient should be directed to a reference centre specialized in treating pregnant diabetics.

b) it is not recommended to periodically monitor $\mathrm{HbA1C}$ values in pregnant women with hypergly- cemia. However, it is advisable to monitor this parameter in clinically doubtful situations as a support for the decision to begin insulin therapy.

c) it is advisable to consider measuring triglycerides concentration as an independent risk factor for fetal macrosomia and preeclampsia, especially in pregnant women in whom hyperglycemia coexists with obesity.

\subsection{Treatment of hyperglycemia during pregnancy}

\subsubsection{Diet and physical activity}

A diabetic diet, combined with appropriately selected and structured physical activity, and an optimization of weight gain in pregnancy, is the basis of hyperglycemia therapy during pregnancy [40]. It is advisable that a pregnant woman diagnosed with diabetes in pregnancy/gestational diabetes mellitus be under the care of a nutritionist, trained in controlling glycemia and aided in modifying her lifestyle [42].

The caloric content of the diet should reflect the recommended gestational weight gain appropriate to her pregestational BMI (refer to Table: Recommended daily calories, as in PGDM).

Patients should be encouraged to self-monitor glucose levels while fasting and an hour after main meals. In unusual cases (e.g. if during a $75 \mathrm{~g}$ oral glucose tolerance test the glucose measured at two hours is higher than one hour after loading; or after a high fat meal) patients may be advised to measure blood glucose two hours after the start of the meal. The main goal of glucose self-monitoring is to capture the highest levels of postprandial glycemia. Randomized trials conducted on small groups of pregnant women with GDM have shown that properly selected physical exercises have a beneficial effect on blood glucose levels. Physical activity of light to moderate intensity, such that engages large muscle groups, is particularly recommended for pregnant women (walking, Nordic walking, swimming, aqua-aerobics, aerobic exercises, cycling, yoga). The exercise session should begin and end with a few minutes of warm-up and stretching. The optimal duration of the actual practice session is 30 minutes for most days of the week (minimum 150 minutes per week). Women who did not regularly exercise before their pregnancy should start with 10-minute sessions and gradually increase their duration [11].

\subsubsection{Pharmacotherapy}

Immediate implementation of therapy with long-acting insulin is advisable if $F B G \geq 126 \mathrm{mg} / \mathrm{dL}$.

In $10-40 \%$ of pregnant women with hyperglycemia diagnosed during pregnancy, diet modification and physical activity alone is insufficient to achieve therapeutic goals (see Table:Target values for blood glucose during pregnancy 
— self-monitoring with a glucometer). In cases of persistent hyperglycemia, following a few days of properly implemented diet and lifestyle modifications, insulin therapy is the treatment of choice.

Oral anti-diabetic drugs are not currently considered standard therapy for hyperglycemia during pregnancy.

It is also advisable to intensify glycemic control and to consider a modification of therapy (addition of insulin therapy) in cases of ultrasonographic evidence of maternal hyperglycemia in the fetus (polyhydramnion, accelerated intrauterine growth, the significant disproportion of fetal head to stomach circumference) despite normal glycemic values reported by patient.

The goal of therapy is to achieve stable normoglycemia and to avoid violent fluctuations in blood glucose levels - hypoglycemia in particular. Due to the observed phenomenon of accelerated starvation during pregnancy, an excessive reduction of carbohydrate intake may lead to ketonuria. Therefore, it is recommended to periodically check this parameter. If acetone levels (in urine) persist despite administering additional insulin dose in cases of hyperglycemia or consuming carbohydrates in hypoglycemia, it is necessary to continue therapy in a hospital setting.

\section{FETAL MONITORING IN PREGNANCY COMPLICATED WITH DIABETES}

\subsection{Ultrasonographic examination} and monitoring of fetal well-being

Since a high percentage (over 70\%) of women with type 1 diabetes suffer from menstrual cycle disorders, hyperandrogenism and polycystic ovary syndrome (PCOS), it is recommended to carefully assess and possibly correct gestational age with the use of ultrasound examination during the first trimester and to compare the result with the date of last menstrual period [43].

The indications for conducting a first trimester combined test in the $11^{\text {th }}-14^{\text {th }}$ weeks of pregnancy, as part of government-guaranteed healthcare services (ultrasound evaluation of chromosomal aberration markers + assessment of serum biochemical markers), are determined on the basis of typical risk factors (age above 35, family history of chromosome aberrations and/or suspected abnormalities during routine first trimester ultrasound examination).

Due to increased risk of structural defects of the fetus, a PGDM patient should be provided with fetal anatomy assessment, including fetal heart evaluation at 18-22 weeks in accordance with the guidelines of the Polish Gynecological Society [44].

Due to increased risk of fetal growth disorders, a PGDM patient should be provided an ultrasound examination of fetal growth and amniotic fluid levels regularly, at least every 4 weeks starting from the $28^{\text {th }}$ week of pregnancy.
Routine assessment of fetal well-being, including Doppler is not recommended in patients with PGDM. It should rather be considered for patients at high risk of intrauterine growth restriction: hypertensive patients and patients with vascular complications of diabetes - diabetic nephropathy in particular [45].

In cases of hyperglycemia during pregnancy initially detected during the first trimester, undiagnosed PGDM should be suspected. For this reason, ultrasonographic monitoring should be conducted in reference centers specialized in the treatment of pregnant patients with diabetes.

It is recommended that daily fetal movement recording (DFMR) be conducted after the $28^{\text {th }}$ week of pregnancy. After the $36^{\text {th }}$ week of pregnancy, cardiotocography with non-stress test (NST) is recommended during each clinical visit and/or daily in hospitalized patients.

Ultrasonographic fetal monitoring should be conducted according to the standards for normal pregnancy and supplemented with additional ultrasound screenings between the $28^{\text {th }}$ and $36^{\text {th }}$ weeks of pregnancy - to assess fetal growth, amniotic fluid levels and macrosomia risk factors [42].

A biophysical profile (BPP) and Doppler sonography flow tests can be considered in cases of improper fetal growth (both SGA and LGA), and in other conditions such as preeclampsia.

Women with GDM should be advised to monitor fetal movements with the "count-to-ten" method if any irregularities are noticed immediately report them to the doctor. The patient should also be advised to report to the physician any observations of reduced or unusual fetal movements after the $28^{\text {th }}$ week of pregnancy.

No specific fetal surveillance protocol has been shown to reduce perinatal mortality in pregnancies complicated with diabetes. If monitoring of fetal well-being is recommended, the frequency of such tests should take into account fetal growth dynamics, a volume of amniotic fluid and co-existence of additional obstetric complications.

\section{CHILDBIRTH}

Childbirth in a patient with PGDM or hyperglycemia diagnosed during pregnancy should take place in a center that is experienced in managing pregnancies complicated with diabetes and possesses an intensive neonatal care unit.

Neither PGDM nor GDM is a contraindication for a natural delivery.

Induction of labour after the $38^{\text {th }}$ week of pregnancy should be considered in PGDM patients due to an increased risk of complications.

According to recommendations of Polish Society of Gynecologists and Obstetricians, in the event of an estimated 
fetus weight exceeding $4000 \mathrm{~g}$, and the difference between $A D$ and BPD exceeding $2.6 \mathrm{~cm}$, induction of labor is contraindicated due to increased risk of shoulder dystocia [46]. The risk of shoulder dystocia can also be assessed by measuring $A C$ and head circumference $(\mathrm{HC})$. Clinical observations show that when this difference (AC-HC) exceeds $4 \mathrm{~cm}$, the risk increases significantly.

Cardiotocographic supervision of pregnant woman should be implemented beginning from the $38^{\text {th }}$ week of pregnancy.

During labour, it is recommended to monitor capillary blood glucose every hour (glucose concentration should be in the range of $70-120 \mathrm{mg} / \mathrm{dL}$ ).

Depending on blood glucose levels, intravenous infusion of either glucose or insulin in a $\mathrm{NaCl}$ solution (infusion pump, $1 \mathrm{IU} / \mathrm{mL}$, with a blood glucose-dependent infusion rate) may be considered.

A patient with GDM may continue pregnancy until spontaneous delivery during the $39^{\text {th }}-40^{\text {th }}$ week of pregnancy provided that: the disease is well managed, patient adheres to the principles of treatment, no other maternal or fetal complications coexist and the estimated fetal weight is between the $10^{\text {th }}$ and $90^{\text {th }}$ percentile, or does not exceed $4000 \mathrm{~g}$. Individuals with poorly managed GDM, or other maternal and/or fetal pathologies, should be individually assessed (attention should be paid to hypertension, preeclampsia, LGA and mother's age $>40$ years). When planning how to resolve pregnancy, the risk of shoulder dystocia should be taken into account for patients with gestational diabetes.

\section{POSTPARTUM CARE}

PGDM patients on insulin therapy require a reduction of insulin dose immediately after delivery (approximately $50 \%$ reduction).

Breastfeeding is not contraindicated in patients with PGDM.

The patient should be informed that breastfeeding may promote hypoglycemia.

Patients with type $2 \mathrm{DM}$ who have used metformin prior to pregnancy may resume therapy with this agent during breastfeeding [47].

PGDM patients in postpartum period should be informed about the importance of using adequate contraception to prevent unplanned pregnancies.

Patients with GDM should be encouraged and motivated to breastfeed for a minimum of 6 months.

In cases of GDM treated with diet alone, the patient should be encouraged to self-monitor her glucose levels while fasting, and two hours after main meals, for a few days after childbirth. If blood glucose levels are within normal range, glycemic control can be discontinued.
In cases of GDM treated with insulin, therapy should be discontinued right after delivery while glucose monitoring should be performed when fasting and two hours after main meals. It is recommended to consider additional glycemic controls between 11:00 PM and 3:00 AM.

It is recommended to perform a $75 \mathrm{~g}$ oral glucose tolerance test six weeks after delivery with the results interpreted according to $\mathrm{WHO}$ guidelines for the general population). In case of negative OGTT results, the test should be repeated every year [10].

According to international recommendations, $\mathrm{HbA1c}$ measurements should be performed 6-13 weeks after delivery. Patients with $\mathrm{HbA} 1 \mathrm{c} \geq 6.5 \%$ should be diagnosed with diabetes mellitus and referred to specialist care [40].

\section{REFERENCES}

1. Robinson A, Nwolise C, Shawe J. Contraception for women with diabetes: challenges and solutions. Open Access J Contracept. 2016; 7: 11-18, doi: 10.2147/OAJC.S56348, indexed in Pubmed: 29386933.

2. WHO. Medical eligibility criteria for contraceptive use Fifth edition 2015. Geneva: WHO 2015.

3. Guerin A, Nisenbaum R, Ray JG. Use of maternal GHb concentration to estimate the risk of congenital anomalies in the offspring of women with prepregnancy diabetes. Diabetes Care. 2007; 30(7): 1920-1925, doi: 10.2337/dc07-0278, indexed in Pubmed: 17446531.

4. Jensen DM, Korsholm L, Ovesen P, et al. Peri-conceptional A1C and risk of serious adverse pregnancy outcome in 933 women with type 1 diabetes. Diabetes Care. 2009; 32(6): 1046-1048, doi: 10.2337/dc08-2061, indexed in Pubmed: 19265024.

5. Egan AM, McVicker L, Heerey A, et al. Diabetic retinopathy in pregnancy: a population-based study of women with pregestational diabetes. J Diabetes Res. 2015; 2015: 310239, doi: 10.1155/2015/310239, indexed in Pubmed: 25945354.

6. Chew EY, Mills JL, Metzger BE, et al. Metabolic Control and Progression of Retinopathy: The Diabetes in Early Pregnancy Study. Diabetes Care. 1995; 18(5): 631-637, doi: 10.2337/diacare.18.5.631.

7. Piccoli GB, Tavassoli E, Melluzza C, et al. Severe diabetic nephropathy in type 1 diabetes and pregnancy--a case series. Rev Diabet Stud. 2013; 10(1):68-78, doi: 10.1900/RDS.2013.10.68, indexed in Pubmed: 24172700.

8. Khoury JC, Miodovnik M, LeMasters G, et al. Pregnancy outcome and progression of diabetic nephropathy. What's next? J Matern Fetal Neonatal Med. 2002; 11(4): 238-244, doi: 10.1080/jmf.11.4.238.244, indexed in Pubmed: 12375677.

9. Mathiesen ER, Ringholm L, Feldt-Rasmussen Bo, et al. Obstetric nephrology: pregnancy in women with diabetic nephropathy--the role of antihypertensive treatment. Clin J Am Soc Nephrol. 2012; 7(12): 2081-2088, doi: 10.2215/CJN.00920112, indexed in Pubmed: 22917698.

10. Diabetology C. 2018 Guidelines on the management of diabetic patients. A position of Diabetes Poland. Clinical Diabetology. 2018; 7(1): 1-90, doi: 10.5603/dk.2018.0001.

11. Kitzmiller JL, Block JM, Brown FM, et al. Managing preexisting diabetes for pregnancy: summary of evidence and consensus recommendations for care. Diabetes Care. 2008; 31 (5): 1060-1079, doi: 10.2337/dc08-9020, indexed in Pubmed: 18445730.

12. Wytyczne ESC dotyczące postępowania w chorobach sercowo-naczyniowych u kobiet w ciąży Kardiologia Polska. 2011; 69: 341-400.

13. Sowinski J, Czupryniak L, Milewicz A, et al. Recommendations of the Polish Society of Endocrinology and Polish Diabetes Association for the management of thyroid dysfunction in type 1 and type 2 diabetes. Endokrynol Pol. 2013; 64(1): 73-77.

14. Hubalewska-Dydejczyk A, Lewiński A, Milewicz A, et al. [Management of thyroid diseases during pregnancy]. Endokrynol Pol. 2011; 62(4): 362-381, indexed in Pubmed: 21879479.

15. Bomba-Opoń D, Hirnle L, Kalinka J, et al. Folate supplementation during the preconception period, pregnancy and puerperium. Polish Society of Gynecologists and Obstetricians Guidelines. Ginekol Pol. 2017; 88(11): 633-636, doi: 10.5603/GP.a2017.0113, indexed in Pubmed: 29303218. 
16. Płudowski $P$, Karczmarewicz $E$, Bayer $M$, et al. Practical guidelines for the supplementation of vitamin $D$ and the treatment of deficits in Central Europe - recommended vitamin D intakes in the general population and groups at risk of vitamin D deficiency. Endokrynologia Polska. 2013; 64(4): 319-327, doi: 10.5603/ep.2013.0012.

17. Bullo $M$, Tschumi S, Bucher BS, et al. Pregnancy outcome following exposure to angiotensin-converting enzyme inhibitors or angiotensin receptor antagonists: a systematic review. Hypertension. 2012;60(2):444-450, doi: 10.1161/HYPERTENSIONAHA.112.196352, indexed in Pubmed: 22753220.

18. Taguchi N, Rubin ET, Hosokawa A, et al. Prenatal exposure to HMG-CoA reductase inhibitors: effects on fetal and neonatal outcomes. Reprod Toxicol. 2008; 26(2): 175-177, doi: 10.1016/j.reprotox.2008.06.009, indexed in Pubmed: 18640262

19. Bateman BT, Hernandez-Diaz S, Fischer MA, et al. Statins and congenital malformations: cohort study. BMJ. 2015; 350: h1035-h1035, doi: 10.1136/bmj.h1035.

20. Kitzmiller JL, Buchanan TA, Siri K, et al. Pre-Conception Care of Diabetes, Congenital Malformations, and Spontaneous Abortions. Diabetes Care. 1996; 19(5): 514-541, doi: 10.2337/diacare.19.5.514.

21. Ray JG, O'Brien TE, Chan WS. Preconception care and the risk of congenital anomalies in the offspring of women with diabetes mellitus: a meta-analysis. QJM. 2001; 94(8): 435-444, doi: 10.1093/qjmed/94.8.435, indexed in Pubmed: 11493721

22. Parretti E, Mecacci F, Papini M, et al. Third-Trimester Maternal Glucose Levels From Diurnal Profiles in Nondiabetic Pregnancies: Correlation with sonographic parameters of fetal growth. Diabetes Care. 2001; 24(8): 1319-1323, doi: 10.2337/diacare.24.8.1319.

23. Mosca A, Paleari R, Dalfrà MG, et al. Reference intervals for hemoglobin A1C in pregnant women: data from an Italian multicenter study. Clin Chem. 2006; 52(6): 1138-1143, doi: 10.1373/clinchem.2005.064899, indexed in Pubmed: 16601066.

24. Jovanovic L, Knopp RH, Kim H, et al. Elevated Pregnancy Losses at High and Low Extremes of Maternal Glucose in Early Normal and Diabetic Pregnancy: Evidence for a protective adaptation in diabetes. Diabetes Care. 2005; 28(5): 1113-1117, doi: 10.2337/diacare.28.5.1113.

25. Lambert K, Holt RIG. The use of insulin analogues in pregnancy. Diabetes Obes Metab. 2013; 15(10): 888-900, doi: 10.1111/dom.12098, indexed in Pubmed: 23489521.

26. Farrar D, Tuffnell DJ, West J, et al. Continuous subcutaneous insulin infusion versus multiple daily injections of insulin for pregnant women with diabetes. Cochrane Database Syst Rev. 2016(6): CD005542, doi: 10.1002/14651858.CD005542.pub3, indexed in Pubmed: 27272351.

27. Wender-Ozegowska E, Zawiejska A, Ozegowska K, et al. Multiple daily injections of insulin versus continuous subcutaneous insulin infusion for pregnant women with type 1 diabetes. Aust N Z J Obstet Gynaecol. 2013; 53(2): 130-135, doi: 10.1111/ajo.12027, indexed in Pubmed: 23316799.

28. Murphy HR, Rayman G, Lewis K, et al. Effectiveness of continuous glucose monitoring in pregnant women with diabetes: randomised clinical trial. BMJ. 2008; 337: a1680, doi: 10.1136/bmj.a1680, indexed in Pubmed: 18818254

29. Yogev $Y$, Ben-Haroush A, Chen R, et al. Continuous glucose monitoring for treatment adjustment in diabetic pregnancies-a pilot study. Diabetic Medicine. 2003;20(7): 558-562, doi: 10.1046/j.1464-5491.2003.00959.x.

30. IOM. Weight Gain During Pregnancy: Reexamining the Guidelines. Washington (DC): National Academies Press (US); Epub 2010/07/30. 2009, doi: $10.17226 / 12584$

31. Rizzo TA, Dooley SL, Metzger BE, et al. Prenatal and perinatal influences on long-term psychomotor development in offspring of diabetic mothers. Am J Obstet Gynecol. 1995; 173(6): 1753-1758, doi: 10.1016/00029378(95)90422-0, indexed in Pubmed: 8610757.
32. Nielsen LR, Müller C, Damm P, et al. Reduced prevalence of early preterm delivery in women with Type 1 diabetes and microalbuminuria--possible effect of early antihypertensive treatment during pregnancy. Diabet Med. 2006; 23(4): 426-431, doi: 10.1111/j.1464-5491.2006.01831.x, indexed in Pubmed: 16620272.

33. Carr DB, Koontz GL, Gardella C, et al. Diabetic nephropathy in pregnancy: suboptimal hypertensive control associated with preterm delivery. Am J Hypertens. 2006; 19(5): 513-519, doi: 10.1016/j.amjhyper.2005.12.010, indexed in Pubmed: 16647626.

34. Abalos E, Duley L, Steyn DW, et al. Antihypertensive drug therapy for mild to moderate hypertension during pregnancy. Cochrane Database Syst Rev. 2007(1): CD002252, doi: 10.1002/14651858.CD002252.pub2, indexed in Pubmed: 17253478.

35. Lausman A, Kingdom J. MATERNAL FETAL MEDICINE COMMITTEE. Intrauterine growth restriction: screening, diagnosis, and management. J Obstet Gynaecol Can. 2013; 35(8): 741-748, doi: 10.1016/S17012163(15)30865-3, indexed in Pubmed: 24007710.

36. ACOG Committee on Practice Bulletins-Obstetrics. ACOG practice bulletin. Diagnosis and management of preeclampsia and eclampsia. Number 33, January 2002. Obstet Gynecol. 2002; 99(1): 159-167, doi: 10.1097/00006250-200201000-00028, indexed in Pubmed: 16175681.

37. RCOG. Hypertension in Pregnancy: The Management of Hypertensive Disorders During Pregnancy.

38. WHO. WHO recommendations for prevention and treatment of pre-eclampsia and eclampsia. 2011

39. Rozporzadzenie Ministra Zdrowia z dnia 9 listopada 2015 r. w sprawie standardów postępowania medycznego przy udzielaniu świadczeń zdrowotnych w dziedzinie położnictwa i ginekologii z zakresu okołoporodowej opieki położniczo-ginekologicznej, sprawowanej nad kobietą w okresie ciąży, porodu, połogu, w przypadkach występowania określonych powikłań oraz opieki nad kobietą w sytuacji niepowodzeń położniczych. 2015.

40. Diabetes Care. 2017; 40(Suppl 1): S114-S119, doi: 10.2337/dc17-S016, indexed in Pubmed: 27979900.

41. Metzger BE, Gabbe SG, Persson B, et al. International Association of Diabetes and Pregnancy Study Groups Consensus Panel. International association of diabetes and pregnancy study groups recommendations on the diagnosis and classification of hyperglycemia in pregnancy. Diabetes Care. 2010; 33(3): 676-682, doi: 10.2337/dc09-1848, indexed in Pubmed: 20190296.

42. NICE. Diabetes in Pregnancy: Management of Diabetes and Its Complications from Preconception to the Postnatal Period. .

43. Escobar-Morreale HF, Roldán-Martín MB. Type 1 Diabetes and Polycystic Ovary Syndrome: Systematic Review and Meta-analysis. Diabetes Care. 2016; 39(4): 639-648, doi: 10.2337/dc15-2577, indexed in Pubmed: 27208367.

44. Polish Gynecological Society - Ultrasound Section Guidelines on ultrasound screening in uncomplicated pregnancy - 2015. 2015; 86(7): 551-558, doi: $10.17772 / \mathrm{gp} / 58642$.

45. Gutaj P, Wender-Ozegowska E. Diagnosis and Management of IUGR in Pregnancy Complicated by Type 1 Diabetes Mellitus. Curr Diab Rep. 2016; 16(5): 39, doi: 10.1007/s11892-016-0732-8, indexed in Pubmed: 26983627.

46. Bomba-Opoń D, Drews K, Huras H, et al. Polish Gynecological Society Recommendations for Labor Induction. Ginekol Pol. 2017; 88(4): 224-234, doi: 10.5603/GP.a2017.0043, indexed in Pubmed: 28509326.

47. Glueck CJ, Salehi M, Sieve L, et al. Growth, motor, and social development in breast- and formula-fed infants of metformin-treated women with polycystic ovary syndrome. J Pediatr. 2006; 148(5): 628-632, doi: 10.1016/j.jpeds.2006.01.011, indexed in Pubmed: 16737874. 